\title{
Crase sem crise: uma proposta didática
}

\begin{abstract}
Resumo
A partir da premissa de que o ensino escolar de gramática tem o papel de formar alunos pensantes, capazes de usá-la de maneira eficaz em suas vidas, procurou-se construir uma proposta didática para aulas de revisão sobre a crase, pois se percebe grande dificuldade dos alunos em utilizá-la, mesmo após terem aulas sobre o assunto em diferentes etapas da vida escolar. Para diagnosticar as dificuldades e fundamentar nossa proposta, foi observada uma turma de $9^{\circ}$ ano de uma escola municipal da cidade de Jaguarão/RS. Também foram aplicados dois testes com os alunos, com o propósito de verificar se realmente houve aprendizagem deste conteúdo. A partir da realidade observada, procurou-se desenvolver uma proposta didática na qual o aluno seja motivado a aprender sobre crase a partir de uma regra única (LUFT, 2014), através de uma metodologia que desenvolva suas capacidades discursivas a partir do trabalho com o gênero notícia on-line, tendo como temática o uso da maconha.
\end{abstract}

Palavras-chave: Crase. Ensino de língua Portuguesa. Proposta Didática.

\section{Verônica Morales da Silva}

Licenciada em Letras Português-

Espanhol e suas respectivas Literaturas pela a Universidade Federal do Pampa - UNIPAMPA. Especialista em Metodologias no Ensino de Línguas e Literaturas pela UNIPAMPA.

Brasil

veronicamoralessilva@gmail.com

\section{Leonor Simioni}

Doutora em Linguística pela Universidade de São Paulo - USP. Professora da Universidade Federal do Pampa - UNIPAMPA. Brasil

leonorsimioni@unipampa.edu.br

\section{Para citar este artigo:}

SILVA, Verônica Morales da; SIMIONI, Leonor. Crase sem crise: uma proposta didática. Revista PerCursos, Florianópolis, v. 18, n.37, p. 36 - 62, maio/ago. 2017.

\section{DOI: $10.5965 / 1984724618372017036$}

http://dx.doi.org/10.5965/1984724618372017036 


\title{
Crasis without crisis: a didactic approach
}

\begin{abstract}
Based on the premise that the role of grammar teaching at school is to educate students into thinking, so that they can effectively use this grammatical knowledge in their everyday lives, we put forward a didactic approach for classes of revision on the crase, because it is noticed that students struggle with the usage of crase, even after having classes on this subject in different schooling stages. In order to diagnose the difficulties and to ground our proposal, we observed review lessons on crase in a gth year class of a public school in Jaguarão/RS. We also applied two tests as a means of verifying what the students had actually learned. From these observations, we put forward an approach in which the students are motivated to learn about crase from one single rule (LUFT, 2014), through a methodology that helps develop the students' discourse abilities through the use of on-line news about the use of marijuana.
\end{abstract}

Keywords: Crase. Portuguese Teaching. Didactic Approach. 


\section{Introdução}

O processo de ensino-aprendizagem de conteúdos gramaticais é bastante complexo: requer interesse e motivação por parte dos alunos, enquanto que por parte dos professores demanda desenvolvimento dessa motivação, através de aulas com objetivos bem definidos, metodologia diversificada e lógica naquilo que se pretende ensinar. Infelizmente, tais características nem sempre estão presentes nas aulas de língua portuguesa. O ensino da crase não é diferente: percebe-se uma dificuldade extrema dos alunos em assimilar os conteúdos de língua portuguesa, e em especial, uma grande dificuldade em utilizar a crase, quiçá porque falta lógica nas regras apresentadas, metodologias ou objetivos bem definidos para auxiliar no processo de ensinoaprendizagem deste conteúdo.

Partindo da perspectiva de que a gramática apresentada na escola tem o papel de formar alunos pensantes, críticos e capazes de usá-la de maneira eficaz em suas vidas, procurou-se diagnosticar e construir uma proposta didática que trate da revisão da crase. Para fundamentar nossa proposta, no ano de 2015, foi observada uma turma de $9^{\circ}$ ano de uma escola municipal da cidade de Jaguarão/RS, que contava com apenas nove alunos, durante as aulas de revisão da crase. ${ }^{1}$ Com esta observação, procurou-se analisar e refletir sobre questões como: dificuldades de aprendizagem, problemas no ensino, falta de leitura de diferentes gêneros textuais, tratamento dos conteúdos com foco no uso, motivação, entre outros.

Além da observação, foram aplicados dois testes, ao final das aulas de revisão do conteúdo crase. Estes testes tiveram o propósito de diagnosticar se realmente houve aprendizagem deste conteúdo, visto que os conteúdos gramaticais aprendidos na escola podem ser de grande valia para a vida, tanto escolar quanto social, dos alunos, já que os mesmos estão inseridos em contextos ricos de atuação, nos quais a língua é falada e/ou escrita a todo momento. Por isso, é essencial discutir estratégias de ensino destes conteúdos, com vistas à reformulação das práticas de ensino da educação básica. Mais que um lugar para simples memorização das regras gramaticais, as aulas de língua

\footnotetext{
${ }^{1}$ Um total de dez aulas.
} 
portuguesa são fundamentais para o desenvolvimento das habilidades de leitura, escrita, compreensão e produção oral, fornecendo ao aluno domínio e desenvoltura na língua. Portanto, é importante abordar aspectos literários e linguísticos, de maneira colaborativa e significativa, com o objetivo de levar ao conhecimento dos alunos o modo como estes fazem parte das suas práticas sociais e, por este motivo, são de suma importância em suas vidas escolares. Além disso, estimular a criticidade e fomentar, nos aprendizes, reflexões sobre o seu papel como leitores, de exprimir do texto as pregnâncias necessárias na construção dos sentidos, encontrando assim as questões explícitas e implícitas no texto.

A linguagem é usada em diversas esferas sociais, e com interlocutores diversos; consequentemente, com adequações ou inadequações linguísticas que causam aos leitores despercebidos fossilizações, muitas vezes, errôneas de formas gramaticais. Como exemplo, temos as redes sociais, que são muito utilizadas pelos jovens; esses e outros usos concretos da linguagem devem ser incorporados pelo professor em suas práticas.

É sabido que o cenário escolar está muito defasado e com objetivos um pouco vagos; obviamente não se pode generalizar, mas é o que se observa em algumas escolas, onde não há um trabalho contextualizado com os gêneros textuais. Apenas percebemos o trabalho com os gêneros de maneira descontextualizada, usando o texto como pretexto para análise gramatical. Sendo assim, é necessário propor que se trabalhe com o ensino dos gêneros textuais e que se proporcione, aos professores, auxílio nessa tarefa, e, acima de tudo, reflexões acerca da prática de aplicar os gêneros textuais e trabalhá-los em conjunto com a gramática.

Por isso, procurou-se desenvolver uma proposta didática na qual o aluno seja motivado a aprender sobre crase, não pelo fato de conhecer e saber aplicar as regras, mas por ser capaz de desenvolver seu raciocínio lógico, quando precisar utilizar a crase. Além disso, será objetivado nesta proposta o desenvolvimento das capacidades discursivas dos alunos, começando o trabalho com a temática da maconha ${ }^{2}$ a partir de

\footnotetext{
${ }^{2}$ Como ficará claro mais adiante, o tema foi selecionado por ter despertado um caloroso debate entre os alunos observados durante a realização da pesquisa.
} 
uma diversidade de gêneros, com abertura de discussões e espaço para que haja produções textuais, reflexão linguística e posteriormente, reescrita dessas produções.

\section{Diagnosticando a crise}

O ensino de língua portuguesa exige dos alunos e dos professores algo fundamental: a consciência linguística. É preciso pensar sobre as estruturas gramaticais, para então desenvolver a aprendizagem sobre os conteúdos a serem estudados. Além disso, é preciso tornar o ambiente escolar um lugar de reflexão sobre as práticas sociais que fazem parte da realidade dos alunos, e quiçá, através destas reflexões, motivá-los a participarem mais das aulas. Contudo, não se pode negar que o ensino-aprendizagem é bastante complexo; por isso, procura-se investigar e propor análises relevantes neste processo, com o intuito de prover dinâmicas com a utilização do conteúdo crase, para que o professor consiga aprimorar seu trabalho com a língua.

De acordo com Bagno (2012, p. 873), o motivo de se ter um fracasso no ensino da crase é o fato de este elemento ser “[...] meramente visual, é simplesmente gráfico, é uma pura convenção da escrita, é desprovido de 'apoio acústico', ou seja: não tem efeito sobre os nossos ouvidos" [grifo do autor]. Para que pudéssemos partir de práticas efetivamente desenvolvidas, foram observadas aulas de Língua Portuguesa no $9^{\circ}$ ano. Nessas aulas, se analisou a maneira como a professora apresentou a crase para os alunos; além disso, procurou-se verificar a questão das reflexões linguísticas, disposição dos exercícios e o uso da língua em estudo.

Dando início às observações, pode-se destacar que a professora ditou o conceito de crase $^{3}$ e algumas regras de uso, a partir da gramática de Cegalla (2008), e a seguir pediu que os alunos escrevessem frases para ilustrar cada regra. Essa atividade poderia ter sido conduzida de maneira mais produtiva, como por exemplo, explorando mais os conhecimentos dos alunos e mesmo o próprio conteúdo, com explicações. Contudo, considera-se bastante relevante a gramática utilizada pela professora para apresentar aos

\footnotetext{
${ }^{3}$ O conceito de crase apresentado foi: "A palavra crase (do grego krásis = mistura, fusão) designa, em gramática normativa, a contração da preposição a com: o artigo feminino a ou as; o pronome demonstrativo a ou as, e o a inicial dos pronomes aquele(s), aquela(s), aquilo".
} 
alunos este conceito; em especial, o fato de ser uma gramática e não um livro didático, já que, segundo Moura Neves (2010, p. 22), “[...] os professores, na quase totalidade, restringem sua fonte de informação ao livro didático em uso" e esquecem o valor informativo das gramáticas.

O conceito de crase já havia sido apresentado, pela mesma professora, a esses alunos numa série anterior, mas foi possível perceber que eles continuavam com bastantes dificuldades, como se ainda não tivessem conhecimento deste conteúdo, que deveria ser apenas revisado. Segundo Kleiman e Sepúlveda,

estudos sobre o ensino de gramática em sala de aula mostram que, geralmente, o professor focaliza o ensino de novas nomenclaturas e a definição de novos objetos linguísticos, não levando em conta aspectos da situação do aluno, como faixa etária, interesses e saberes, nem a falta de atividades didáticas que facilitem a aprendizagem. (KLEIMAN; SEPÚLVEDA, 2012, p. 13)

Para a autora, é importante conhecer a turma, seu nível linguístico, sua idade e seus interesses, para adentrar ao conteúdo, que não pode ser apresentado como um produto pronto, e sim como algo construído pelos alunos, a partir de seus conhecimentos, com o propósito de sanar as dúvidas que ainda persistem. Infelizmente, é comum as aulas de português apresentarem conteúdos já estudados como algo novo, sem fazer relação ao que já foi aplicado - muitas vezes pela mesma professora - na série anterior. Isso não contribui para que o aluno progrida em relação ao seu nível de aprendizagem.

Na aula seguinte, a educadora explicou outras regras que faltavam: onde não se usa crase e os usos facultativos. Em seguida, passou dezesseis frases, nas quais os alunos tinham que colocar a crase, se necessário, e justificar. Os alunos realizaram com bastantes dificuldades todas as frases propostas; mais adiante, foi feita a correção no quadro. Nesta atividade, pode-se perceber que os alunos não só mostraram dificuldades com o uso da crase, mas também com outras questões linguísticas, tais como concordância verbal e nominal, plural e singular, letras maiúsculas no meio de frases, entre outros. 
É preciso considerar ainda que falar em crase implica discutir questões gramaticais diversas, como transitividade verbal, regência verbal, classes de palavras, entre outros. Então, o trabalho será bem maior do que apenas listar regras, pois teremos que tratar de outros assuntos para adentrar ao conceito da crase. Também é importante expor aos alunos que, embora seja caracterizada pelo acento grave, a crase não é um acento; essa é uma das principais dificuldades por parte dos alunos, já que acreditam que crase é um acento.

Sabe-se que crase é a junção da preposição "a" com o artigo definido "a(s)", ou ainda da preposição "a" com as iniciais dos pronomes demonstrativos aquela(s), aquele(s), aquilo ou com o pronome relativo a qual (as quais). Contudo, será que os alunos dominam todas essas classes de palavras apresentadas? Não se pode garantir, mas podemos ativar seus conhecimentos prévios, ou, antes de iniciarmos a conversa sobre a crase, introduzir estes assuntos, com o propósito de retomá-los e esclarecer ainda mais o conceito de crase.

Neste momento, seria interessante relacionar aspectos linguísticos com os gêneros textuais, já que pensar em gêneros e, sobretudo, refletir sobre as formas de expressão da língua, propondo momentos de leitura, análise e produção, é fundamental para que o aluno consiga ampliar as suas competências comunicativas. De acordo com Dionísio, Machado e Bezerra (2010, p. 44). “[...] as aulas podem deixar de ter um caráter dogmático e/ou fossilizado, pois a língua a ser estudada se constitui de formas diferentes e específicas em cada situação e o aluno poderá construir seu conhecimento na interação com o objeto de estudo" Em vista disso, vemos o quanto a abordagem dos gêneros no processo de ensino e aprendizagem da língua portuguesa é importante, auxiliando em diferentes fatores como: consciência linguística, reflexões sobre as similaridades e diferenças estruturais entre os gêneros trabalhados, e o diálogo sobre os principais equívocos produzidos pelos alunos, para que estes não sejam fossilizados, e sim sanados, na aula de língua portuguesa.

Outro exercício aplicado pela professora envolvia marcar verdadeiro ou falso, justificando. Mais adiante, a professora solicitou que os alunos escrevessem no quadro a correção, atribuindo nota para quem fizesse no quadro os exercícios. Atribuir valores às 
atividades realizadas pelos alunos é um fator de motivação, já que os incentiva a fazerem os exercícios propostos; porém é uma motivação voltada à realização dos exercícios. Deveria haver também uma motivação voltada à aprendizagem do conteúdo, o que faria com que o aluno se interessasse mais pela aprendizagem e dominasse o conteúdo.

Em conversa posterior com a docente, chegou-se à conclusão de que falta motivação por parte dos professores porque falta interesse por parte dos alunos; mas será que a motivação não auxilia no interesse? Se o professor, por exemplo, questionar os alunos, com perguntas como: Por que vocês estão aprendendo a usar a crase? Para que se ensina isso? Onde se usa?, suscitando a reflexão, isso não engajaria os alunos? Não os motivaria a aprender?

Como última atividade sobre crase, foi solicitada a construção de frases para cada regra de uso, não uso ou caso facultativo da crase. Posteriormente, os alunos teriam que levar as frases elaboradas à mesa da professora, para que ela fizesse as correções necessárias. Acredita-se que seria mais interessante se o conceito de crase fosse, ao final das atividades, construído colaborativamente com ajuda de todos os alunos, para que eles tivessem a oportunidade de atribuir suas impressões, refletindo sobre o que aprenderam. Neste processo, é possível que houvesse erros, mas dar a forma correta não trará aos alunos momentos para que eles possam construir o conhecimento.

Após a observação das aulas, elaboramos e aplicamos dois testes, com o objetivo de diagnosticar se realmente os alunos conseguiram aprender o conteúdo crase, já que este foi visto na série anterior e estaria sendo revisado nesta série. Além disso, procurouse investigar qual era a relação das regras gramaticais com o uso, ou seja, se os alunos conseguiriam usar as regras que haviam aprendido.

O primeiro teste, aplicado logo após o término das aulas de revisão, contou com quatro alternativas de marcar, nas quais se usa ou não se usa crase, de acordo com as regras aprendidas nas aulas observadas. Estas alternativas contavam com questões sobre o uso da crase, e também envolviam outros conteúdos como transitividade verbal, palavra masculina e/ou feminina, verbo, pronome de tratamento antecedido de verbo transitivo direto. Com esta atividade se objetivou diagnosticar não apenas o 
conhecimento das regras gramaticais sobre crase, mas também de alguns conteúdos indispensáveis na compreensão da crase, como é o caso da transitividade verbal.

Os resultados mostraram que os erros ultrapassaram os acertos, ou seja, houve mais inadequações do que adequações, especialmente nos casos em que era necessário que os alunos relacionassem crase com transitividade verbal. Já nas questões em que a aplicação das regras quanto à utilização da crase era suficiente, houve mais adequações.

Em seguida, foi realizada uma atividade de produção de um pequeno parágrafo, no qual o aluno teria de escrever sua opinião sobre o combate às drogas, respondendo: “O que você acha que podemos fazer ou o que pode ser feito para combater as drogas?”. Nesta atividade, teriam de ser ativados conhecimentos sobre construção de parágrafo, coerência, coesão, concordância nominal e verbal, reflexões sobre a temática proposta, além do provável uso da crase, já que na íntegra da questão estavam escritas as expressões "combate às drogas" - com crase, e "combater as drogas" - sem crase, para que o aluno percebesse a diferença e usasse conforme sua aprendizagem. ${ }^{4}$ Apenas dois alunos usaram, em sua resposta, a expressão “combate às drogas”: um deles utilizou a crase, o outro não.

Com esta atividade ficou claro que há falhas na utilização da crase, uma vez que os alunos não dominam sua utilização e aplicação, apenas memorizam as regras mais comuns. Uma das hipóteses da causa destas falhas é o fato de que, como afirma Bagno (2012, p. 874), "as explicações tradicionalmente oferecidas para o ensino do acento indicador de crase são confusas porque não se inspiram na realidade da língua falada pelos brasileiros [...]". Por exemplo: durante as aulas observadas, a professora usou a frase "Ele retornará à casa assim que escurecer"; nela, os alunos teriam que dizer se o uso da crase estava correto, justificando. Contudo, é muito mais usual dizermos "Ele retornará para casa assim que escurecer". 5

\footnotetext{
${ }^{4} \mathrm{Na}$ expressão combate às drogas, usa-se o acento indicador da crase, pois combate é um substantivo transitivo, logo pede uma preposição. Já na expressão combater as drogas, não se usa o acento indicador da crase, pois combater é um verbo transitivo direto e não pede preposição. Portanto, o aluno teria que observar essas diferenças e usar corretamente a crase em seu texto.

5 A preposição "a", em geral, é pouco empregada na fala cotidiana. Para aprender a crase, é preciso primeiro aprender o uso da preposição.
} 
Outra hipótese para as falhas ocorridas na utilização da crase é o fato de que as regras se apresentam dissociadas de outros conteúdos afins; por exemplo, sabe-se que há crase antes de "senhora", "senhorita" e "dona", mas temos que saber que, quando esses pronomes forem complemento de um verbo transitivo direto, não se deve empregar a crase.

Além disso, outros problemas linguísticos foram recorrentes: uso de letras maiúsculas no meio de frases, falta de entrada de parágrafo, emprego equivocado dos porquês, falta de concordância, problemas de ortografia, entre outros, como ilustram os exemplos abaixo:
a. Tem que mandar as pesoas que ten problemas con as drogas para rehad
b. Eu acho que não se pode fazer nada, porque a pessoa que usa droga ta ali por que quer. Não digo que não vai se ajuda a pessoa tentar sair disso.
c. Distribuir cartas e etc. tudo bem isso talves não ajude em nada mais serve ja para outras pessoas refletir E para combate as drogas parar de vende.

d. Se o cigarro e a bebida é liberado, porque não legalizam as drogas mais leves?

Estes problemas foram diagnosticados na construção do parágrafo, na qual percebe-se que falta consciência linguística, falta leitura, e acima de tudo, há falta de coerência e sincronicidade na apresentação dos conteúdos, que, por serem afins, precisariam ser relacionados e bem preparados para serem discutidos em aula.

A partir do teste, ficou claro que os alunos sabem utilizar as regras; o problema é que as regras apresentadas são falhas e, portanto, se tornam insuficientes. Por exemplo, uma das questões trazia um verbo transitivo direto seguido de palavra feminina ("entregou a encomenda"). O grande número de alunos que "corrigiu" o exemplo, colocando crase, indica que não há reflexão, apenas aplicação cega das regras ("usa-se crase antes de palavra feminina"). ${ }^{6}$

\footnotetext{
${ }^{6}$ De fato, nos exercícios passados pela docente ao longo das aulas observadas, não havia casos desse tipo; em todos os exemplos, os discentes poderiam olhar exclusivamente para o "a" e para a palavra seguinte, sem nem ler a frase. Critica-se o uso de frases soltas no ensino de gramática, mas vemos que a questão é um pouco mais complexa, pois mesmo frases soltas são uma espécie de contexto (gramatical, ao menos). O problema é que os discentes sequer precisam lê-las para responder os exercícios.
} 
Pode-se perceber que os alunos não conseguem fazer relações do conteúdo crase com os outros conteúdos já estudados, como por exemplo, regência verbal. É fundamental que o aluno faça relações - tanto de conteúdos gramaticais, quanto de componentes culturais, pois quanto mais significações o estudante fizer, mais eficaz será seu aprendizado. Para tanto, dependerá do auxílio do professor, que além de fazer/ mostrar as relações entre conteúdos afins, estimulará o aluno a construir relações significativas para seu aprendizado.

Para concluir o primeiro teste, foi solicitado que, com suas palavras, os estudantes formulassem o conceito de crase. Esta atividade foi pensada como forma de analisar e diagnosticar o que os alunos entenderam por crase, partindo da hipótese de que muitos confundem crase com acento e que, mesmo sendo revisão, os alunos não têm domínio deste conceito. As respostas a seguir são representativas ${ }^{7}$ :

(2) a. Acho que crase é necessário para ter sentido algumas frases. Não é apenas um acento.

b. Crase é a junção de quais vogais tônicas ( $a+a=a ̀)$ constituído por varias regras.

c. Crase é acento muitas vezes usado para podermos escrever as palavras corretamente.

d. É um acento que vai somente na letra "à" antes de substantivos.

A hipótese de que os alunos têm muita dificuldade em diferenciar crase de acento foi claramente confirmada, já que alguns alunos não conseguiram distinguir o sinal gráfico da crase, e associaram a crase com um conjunto de regras, a construções de sentido, entre outros.

Após a análise do primeiro teste, ficou nítido que existe um acordo tácito entre a professora e seus alunos: ela apresenta exemplos nos quais a regra funcionará sem a necessidade de fazer relações, restando-lhes simplesmente aplicar a regra para resolver os exercícios propostos. Não é necessário olhar para o contexto da frase, apenas decorar as regras.

Aproximadamente um mês depois da aplicação do primeiro, foi aplicado o segundo teste, com o objetivo de diagnosticar se o conteúdo foi realmente fixado pelos

\footnotetext{
7 Também é importante destacar que alguns alunos não responderam.
} 
alunos. Este teste contou com cinco alternativas de marcar, nas quais os alunos teriam de dizer se deviam ou não utilizar a crase. Duas alternativas foram pensadas para que os educandos relacionassem a transitividade com o uso da crase, já que estes dois conteúdos haviam sido estudados em séries anteriores. Nas demais alternativas, bastava aplicar corretamente as regras apresentadas pela professora.

Os resultados não foram diferentes do primeiro teste: os alunos mostraram ter decorado algumas regras quanto ao uso da crase (sabem que se usa crase antes de palavras femininas, não se usa crase diante de palavras masculinas e não se usa crase diante de verbos), mas é clara a dificuldade que enfrentam para fazer associações. Com este teste ficou constatado: os alunos aprendem a decorar regras, mas não a pensar sobre sua aplicação, relacionando-as com outros conteúdos.

É interessante ressaltar que, no plano de conteúdos das escolas do município de Jaguarão referente ao Ensino Fundamental, está estabelecido que, desde o $8^{\circ}$ ano, o aluno passará a conhecer a crase; no $9^{\circ}$ ano, apenas se fará uma revisão deste assunto. Contudo, no plano curricular, os conteúdos crase, regência e transitividade não são associados e sequer estão previstos para o mesmo bimestre. Nota-se então que este problema vai além da sala de aula, fazendo parte também do documento oficial que rege o ensino da língua portuguesa nas escolas do município. Apesar disso, é papel do professor transformar o ensino da língua num fenômeno social e cultural, no qual o aluno entenda como ocorre o processo de formação das estruturas linguísticas, sabendo articular o uso com a aprendizagem.

Como um fechamento das atividades de coleta de dados e como forma de agradecimento, entregamos aos alunos o primeiro teste, dialogando a respeito dos principais equívocos e sanando algumas dúvidas sobre a crase. Nesta conversa, alguns alunos quiseram saber por que havíamos perguntado sobre o combate às drogas, já que este não é um tipo de assunto tratado em sala de aula pela maioria dos professores e não tem relação com crase.

Para responder esta questão, primeiramente dissemos que todos precisam pensar, refletir, desenvolver opiniões, críticas, argumentos, enfim, respaldo para que se 
tornem cidadãos preocupados com o desenvolvimento da sociedade. Além disso, que é necessário articular questões culturais na escola e principalmente nas aulas de português, fazendo com que o estudo linguístico deixe de ser um apanhado de regras e se torne um apanhado de boas aplicações destas regras em nosso dia a dia. Neste momento, alguns alunos disseram ser usuários de maconha e, por isso, acreditavam que cada um teria que cuidar da sua vida; ademais, combater a maconha seria "muito difícil". Enfim, este debate gerou várias questões; uma delas foi o uso da maconha na vida das pessoas.

Tendo em vista a repercussão e a surpresa das provocações do debate que surgiu a partir da entrega dos testes, se pensou em uma proposta alternativa para o ensino de crase, na qual se integre a gramática com elementos socioculturais, e que tenha o intuito de mostrar aos educandos os riscos do consumo da maconha. Além disso, pela promoção de reflexões, diálogos e debates podem-se formar alunos críticos e pensantes, capazes de articular sobre este fator cultural com domínio e, a partir disso, trabalhar a crase. Para Bagno (2012, p. 29):

São práticas socioculturais que exigem um aprendizado relativamente longo e contínuo para que o aprendiz se apodere delas a ponto de exercê-las com habilidade e destreza. Sendo assim, o ensino da leitura e da escrita, e o acesso aos discursos sociais que se valem delas, é a tarefa primordial da educação em língua materna na escola.

Nesse sentido, é importante fazer um trabalho que integre o ensino da leitura e escrita com assuntos sociais que fazem parte do cotidiano dos alunos. Obviamente, se trata de um trabalho de longa duração; contudo, nessa proposta, tentaremos desenvolver atividades para que o aluno atinja domínio do conteúdo e da temática escolhida, em um total de dez momentos.

\section{Encarando a crise}

A crase é um conteúdo gramatical estudado em pelo menos três anos da vida escolar dos alunos; no entanto, não é fixado ou aprendido por eles, como foi observado 
nas aulas e diagnosticado nos testes. Inclusive, os estudantes alegam ter muitas dificuldades em assimilar este conteúdo. Evidentemente, não há culpados; o que existe é falta de foco no uso e análise do processo linguístico, pois geralmente estudamos tal conteúdo para deixar guardado no caderno e nunca mais usarmos. Além disso, segundo Luft (2014, p. XI) erra-se no ensinar crase, porque se ensinam regras demais; “a regra é uma só: acentua-se o ‘a' duplo ( $\mathrm{a}+\mathrm{a}=\mathrm{a})$ )”.

No currículo escolar das escolas municipais de Jaguarão/RS, por exemplo, os alunos se deparam com a crase no $8^{\circ}$ e $9^{\circ}$ anos do Ensino Fundamental e no $3^{\circ}$ do Ensino Médio. Cabe observar que nos dois últimos anos este conteúdo era, na teoria, para ser dado como revisão, mas na prática acaba sendo aplicado como matéria nova. No caso da turma analisada, a professora alega que os alunos não aprenderam nos anos anteriores, então não seria possível apenas revisar neste ano.

Diante dessa realidade, entende-se que seria primordial tratar a crase com maior articulação; ora, se os alunos não estão aprendendo, logo o professor terá de mudar sua dinâmica, promovendo reflexões, já que na aula do $9^{\circ}$ ano, relatada neste estudo, os alunos sabem que já viram crase e podem se lembrar de algo. Portanto, seria mais interessante que dialogassem sobre o que seria a crase ou do que eles se recordam quando pensam neste conceito, ou até mesmo, o que foi estudado sobre a crase e onde ela é empregada, fazendo com que os alunos não só interajam, mas que retomem o que já foi trabalhado, fomentando neles a capacidade de pensar, discutir, criticar, entre outras - capacidades estas que os alunos ignoram quando fazem apenas exercícios de copiar a regra tal qual foi apresentada pelo professor.

Pensando nestes pontos, se percebe o quanto é importante criar propostas para o ensino-aprendizagem da crase nas quais seja objetivado o aprendizado através do uso da língua, para que o aluno consiga desenvolver suas capacidades discursivas orais e escritas. De acordo com esta perspectiva, serão propostas atividades de diálogo, debates, produção textual, consciência e análise linguística e estrutural, entre outros, em um processo gradativo que contará com dez momentos, de acordo com o tempo que foi observado, ou seja, dez aulas, e terá como temática a maconha. A escolha deste tema foi 
pensada pelo fato de os alunos não se sentirem encorajados a tratar de assuntos que não se relacionam com o conteúdo da aula. Passamos então à descrição das atividades.

\subsection{Primeiro momento}

Objetivos: Atribuir sentido ao texto a partir dos conhecimentos prévios dos alunos, e orientá-los, com a estratégia de leitura protocolada ${ }^{8}$, à prática da compreensão textual autônoma.

Será entregue aos alunos uma notícia ${ }^{9}$ para que percebam como efetivamente são apresentadas as notícias em portais on-line. Além disso, se objetivará introduzir a temática da maconha a partir de uma proposta geral que é, neste caso, o julgamento realizado pelo Supremo Tribunal Federal para decidir se a posse de drogas é crime ou não. A atividade realizada com o apoio deste texto será uma leitura protocolada, que contemplará questionamentos como os seguintes, realizados oralmente:

- A partir do título, do que trata o texto?

- Quem é o ministro apontado no título?

- Através do título, você consegue perceber qual o gênero do texto?

- A frase abaixo do título, o que sugere?

- Podemos acreditar que Gilmar Mendes é a favor ou contra a descriminalização da maconha?

- Sobre a imagem trazida pelo autor, qual seria a sua impressão?

- Procure o significado da palavra blacklash.

- O que significa ser um ministro progressista?

- O que prevê a Constituição Federal sobre as drogas?

\footnotetext{
${ }^{8}$ A técnica da leitura protocolada consiste em uma atividade que envolve a produção de inferências pelo leitor. Tipicamente, o professor lê o texto segmentando-o em partes, desde o título; a cada parte lida, são feitas perguntas para os alunos, tanto para avaliar a compreensão do que foi lido, quanto para estimulálos a fazer previsões sobre o que poderá vir a seguir no texto, a partir do que já foi lido e do que sabem sobre o assunto e/ou sobre a estrutura do gênero textual.

${ }^{9}$ Ministro defende legalização da maconha. Disponível em: <http://noticias.terra.com.br/brasil/ministro-dostf-diz-que-brasil-deve-legalizar-a-maconha-e-ver-como-isso-funciona-na-vida real,8c594bb92b4337787846ba036ee371fevzooRCRD.html>. Acesso em: 19 mar. 2017.
} 
- Por fim, de acordo com a leitura do texto, por que o ministro Luís Roberto

Barroso defende a descriminalização do consumo da maconha?

\subsection{Segundo momento}

Objetivos: Conhecer ou relembrar características e a definição do gênero textual notícia.

Serão entregues aos alunos algumas notícias, ${ }^{10}$ extraídas da internet, que tratam de diferentes aspectos relacionados ao uso da maconha (uso medicinal, consequências do uso da maconha na adolescência) e também à sua legalização. Após realizar, em duplas ou individualmente, uma leitura silenciosa, cada dupla ou aluno contará à turma o que entendeu de sua notícia, uma vez que cada estudante receberá uma notícia diferente. Portanto, os alunos terão de ler, compreender, interpretar e transpor com suas palavras o que acharam pertinente no texto, além de analisar o gênero, a sua estrutura linguística e denominá-lo, justificando sua denominação. A partir dos textos, os alunos deverão responder as seguintes questões:

- Qual é a temática encontrada no texto?

- Como geralmente é estruturado?

- Onde circula?

- Quais são os recursos linguísticos empregados neste texto?

- Quem escreve?

- A que leitor se destina?

- Qual é o estilo predominante?

- Qual é a finalidade?

- Qual é o nível linguístico empregado?

10 O uso da maconha na adolescência. Disponível em: <http://veja.abril.com.br/noticia/saude/uso-demaconha-na-adolescencia-causa-perda-de-memoria-no-futuro>. Acesso em: 19 mar. 17. O barato da maconha não deu certo no Uruguai. Disponível em: <http://veja.abril.com.br/mundo/o-barato-damaconha-nao-deu-certo-no-uruguai/>. Acesso em: 19 mar. 2017. Maconha diminui chances de jovem conseguir diploma. Disponível em: <http://veja.abril.com.br/noticia/saude/maconha-diminui-chances-dejovem-conseguir-diploma/>. Acesso em: 19 mar. 2017. Pais lutam na justiça por liberação de remédio derivado da maconha. Disponível em: <http://g1.globo.com/fantastico/noticia/2014/03/pais-lutam-najustica-por-liberacao-de-remedio-derivado-da-maconha.html>. Acesso em: 19 mar. 2017. 
Esta tarefa terá como objetivo levar o aluno a pensar sobre qual será a provável nomenclatura atribuída ao gênero escolhido e como ele se faz presente na sociedade atual. Caso os alunos tenham dificuldades em realizar esta atividade, será proposta a prática da leitura protocolada, que será realizada individualmente ou em duplas. Além disso, será aberto um debate sobre o enfoque que cada autor deu para o uso da maconha. Por fim, será proposta uma pesquisa que deve ser feita em casa, sobre o conceito do gênero notícia.

\subsection{Terceiro momento}

Objetivos: Promover a comunicação social e o desenvolvimento da capacidade discursiva e escrita dos alunos, além de retomar as principais temáticas trazidas a partir do debate da aula anterior.

Discussão das pesquisas realizadas pelos alunos, na qual cada um fará contribuições acerca do gênero notícia: onde circula, quem lê, como se estrutura, que elementos o compõem/caracterizam. Essas contribuições serão escritas no quadro pela professora; além disso, se questionará sobre o uso deste gênero. Como forma de explicitar, se restarem dúvidas acerca do conceito de notícia, a professora exibirá uma espécie de resumo, no qual constarão as principais características de uma notícia.

Para finalizar esta atividade, será feita uma retomada das notícias apresentadas na aula passada, de acordo com a sua temática.

\subsection{Quarto momento}

Objetivos: Desenvolver a escrita e o pensamento crítico.

Neste momento, será proposta a escrita de uma notícia, de acordo com a temática sugerida pela professora, que serão argumentos favoráveis e contrários ao uso da 
maconha, a partir de uma matéria on-line. ${ }^{11}$ A questão da imparcialidade das notícias também será tratada, para que o aluno a leve em conta na hora de produzir seu texto, procurando ser imparcial. Ao final da aula, os alunos terão de entregar as produções para que a professora possa fazer as correções necessárias, além de apontar os principais problemas linguísticos e discuti-los com a turma. Mais adiante, se fará uma socialização do trabalho realizado, além de discussões sobre o papel dos gêneros textuais na sociedade atual, fazendo com que os alunos, além de saberem identificá-los, conheçam suas funcionalidades, estabilidades e variedades que os transcendem. Sobretudo, para que saibam argumentar sobre determinados assuntos, como é o caso em relação ao uso e à legalização da maconha.

\subsection{Quinto momento}

Objetivos: Analisar a construção do gênero notícia e adequar o uso da linguagem com a prática da escrita.

Proposta de reescrita das produções por parte dos alunos. Neste momento, serão feitas as correções necessárias, a partir das explicações dadas pela professora sobre os equívocos, tanto linguísticos quanto composicionais, de cada produção. Depois, será feita uma reflexão sobre o trabalho apresentado, apontando para a ocorrência diária de certas inadequações tanto com relação à constituição dos gêneros, quanto aos equívocos linguísticos - em especial, quanto ao uso correto ou inadequado da crase, além da entrega, por parte dos alunos, da produção final das notícias.

\subsection{Sexto momento}

Objetivos: Estimular o raciocínio crítico; discutir e levantar hipóteses sobre o conceito de crase para apresentação das ideias dos alunos.

\footnotetext{
11 Maconha: é hora de legalizar? Disponível em: <http://zh.clicrbs.com.br/especiais-zh/zh-maconha-e-horade-legalizar/>. Acesso em: 19 mar. 2017.
} 
Retomar com os alunos os conhecimentos adquiridos nos anos anteriores. Nesta atividade se fará uma espécie de construção coletiva do saber, pois os alunos terão de procurar em suas notícias frases em que ocorra a crase e, além disso, através do contexto de cada frase, retomar conteúdos como artigo, preposição e pronomes, para então chegar à crase.

A ideia nesta atividade é que todos os alunos participem, independente de não saberem absolutamente nada sobre estes assuntos, pois aqui se levantarão hipóteses que serão confirmadas no final deste momento. Caso os alunos não saibam, serão dados exemplos de uso de crase retirados das notícias apresentadas, como por exemplo:

- Droga altera o hipocampo, região do cérebro associada à memória de longo prazo;

- Quando se submeteram à pesquisa, tinham vinte e poucos anos e haviam deixado de consumir a droga há cerca de dois;

- Os uruguaios não se sentem à vontade em passar seus dados para uma entidade estatal;

- Para a Associação Brasileira de Psiquiatria, ainda faltam evidências de que o Canabidiol funcione e não traga prejuízos à saúde.

A respeito das frases retiradas das notícias, se questionará o que há de comum entre elas, para que os alunos possam inferir e atribuir significações próprias, com o intuito de mostrar que em todos os exemplos há palavras femininas após a crase. Mostraremos também que há casos em que encontramos uma palavra feminina após um "a", porém não ocorre crase:

- Segundo novo estudo, adolescentes que consomem a droga diariamente são $60 \%$ menos propensos a concluir estudos na escola ou em ensino superior. ${ }^{12}$

Mais adiante, será solicitado à turma que faça uma roda para discutir estas questões, sempre pensando no uso, com perguntas como: O que é um artigo? Onde ele aparece com mais frequência? E a preposição, onde ocorre? Quais são as mais recorrentes?

\footnotetext{
${ }^{12}$ Como em um dos textos não há nenhuma ocorrência de crase, será problematizado o não uso da crase diante da palavra "droga", já que nos outros textos isso acontece.
} 
Vocês já estudaram estes conteúdos? Onde aparecem os artigos? Entre outros. Caso eles não se recordem destes conceitos, se trabalhará individualmente cada um, para que mais adiante os alunos possam assimilar o conteúdo crase com mais profundidade e domínio.

\subsection{Sétimo momento}

Objetivos: Perceber como ocorre a contração do artigo com a preposição para formar a crase, além de analisar e explicar junto com a turma como ocorre o processo da crase e como podemos raciocinar para decidir se há ou não crase, a partir da construção conjunta do exercício.

Neste momento, a professora pedirá aos alunos que escrevam e apresentem à turma frases empregando artigos e preposições. Mais adiante, será perguntado como pronunciamos "casa amarela", para que o aluno chegue à conclusão de que falamos "casamarela", ou seja, ocorre uma junção das duas sílabas átonas (a+a) -uma crase. Além disso, se questionará quanto à junção em outras palavras, como "amigo oculto" ("amigoculto"), e também se mencionará o fato de que com sílabas tônicas este processo não acontece - por exemplo, não dizemos “casampla”, e sim, "casa ampla”. Também se questionará se pronunciamos "fomos para a Lagoa" ou "fomos pra Lagoa".

Posteriormente, se colocará no quadro a seguinte frase: "Vamos a Lagoa" e se questionará a ocorrência ou não da crase. Como forma de motivar e orientar o aluno no seu raciocínio, esta frase será substituída por "Vamos ao lago", na qual ocorrem uma preposição e um artigo; se com a palavra masculina "lago" aparecem a preposição e o artigo, deve-se usar a crase em "Vamos à Lagoa", pois ali haverá, também, uma preposição ("a") e um artigo ("a").

Por fim, será realizado o seguinte exercício:

Empregue a crase, quando necessário, utilizando o raciocínio feito na atividade anterior:

a) Escreveu um bilhete a caneta. [lápis]

b) Não vou a festas. [encontros] 
C) Agradeça a sua tia. [seu tio]

d) Rezamos a Nossa senhora. [Nosso senhor]

e) Chegamos a casa de noite. [lar]

f) Antes da tempestade, o pescador voltou a terra. [mar]

g) Moro a uma quadra da sua casa. [quilômetro]

h) Falei a senhora. [senhor]

i) O lustre pode cair a qualquer hora. [momento]

j) Assisti a duas novelas. [filmes]

k) Entregaram o prêmio a três alunas. [alunos]

I) Entregaram o prêmio as três alunas. [alunos]

m) Estas disposta a estudar?

n) Escrevi a Márcia. [Márcio]

o) Fiz um café as minhas amigas. [meus amigos]

p) Vou a Bahia. [Rio de Janeiro]

q) Visitei aquele cinema. [teatro]

r) Estou a espera de um amor. [aguardo]

s) Cigarro faz mal a saúde. [pulmão]

Para confecção deste exercício, primeiramente a professora fará junto com os alunos as frases iniciais, depois solicitará que cada aluno vá ao quadro e, com a sua ajuda, decida se há ou não crase.

\subsection{Oitavo momento}

Objetivos: Retomar as produções dos alunos e perceber as ocorrências da crase; exercitar o uso, não uso e uso facultativo da crase, através de imagens.

Neste momento, será solicitado que os alunos retomem suas produções, para que percebam como utilizaram a crase nos seus textos, se a utilização foi correta ou não, ajustando os equívocos. Posteriormente, a professora retomará com a turma as frases mais problemáticas dos textos apresentados. Além disso, as notícias trazidas servirão de 
aporte para relacionar a crase com a regência, pois será delas que os alunos irão extrair os exemplos de crase.

Se no exercício anterior houver erros, a aplicação da próxima atividade é opcional. Caso não haja muitos equívocos, a professora projetará as imagens abaixo ${ }^{13}$ em um datashow:
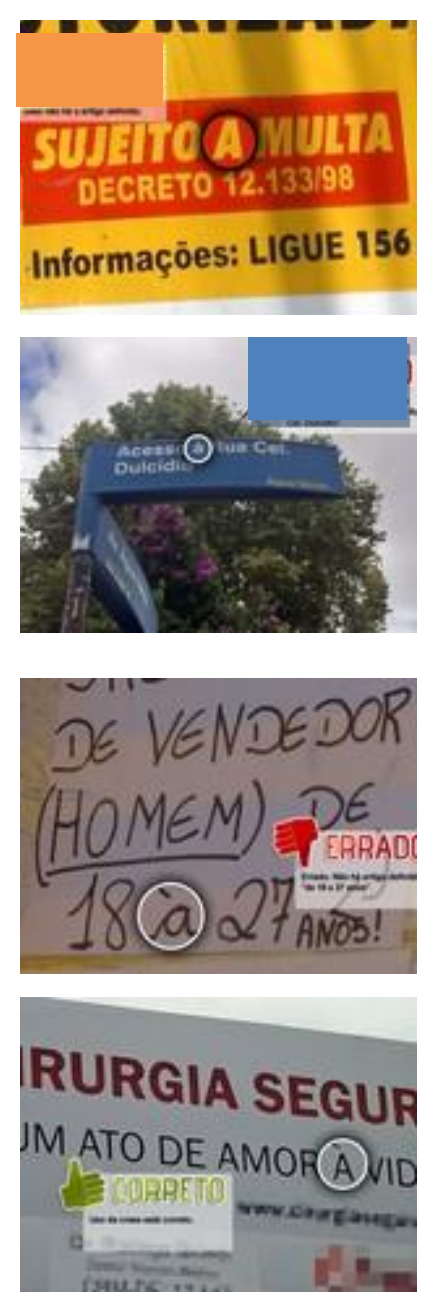
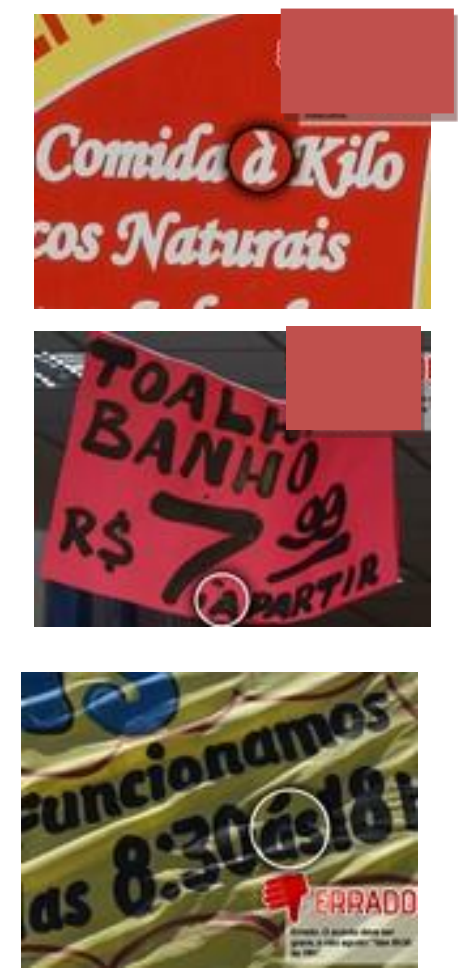
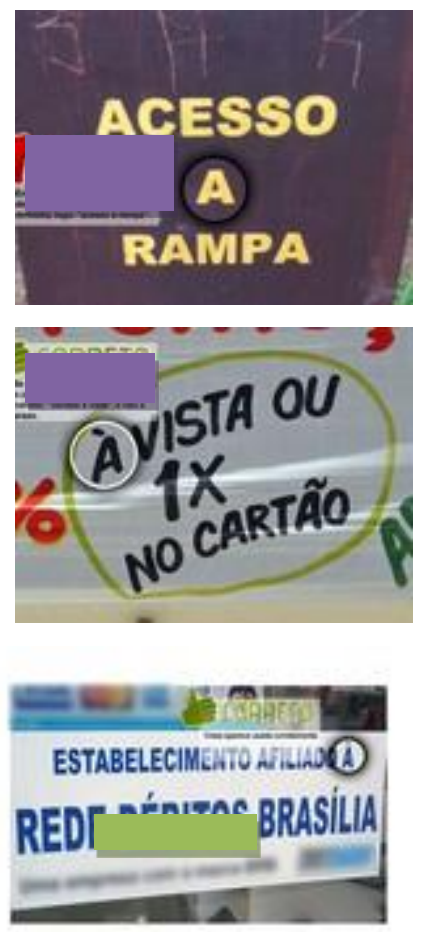

Nessas faixas, banners ou placas são apresentados empregos concretos da crase, para que os alunos possam exercitar o que foi aprendido, com intuito de formar leitores críticos. Após analisar as imagens, os alunos terão de determinar se as crases foram empregadas corretamente, justificando e dando suas contribuições oralmente. No final

\footnotetext{
${ }^{13}$ Fotos com exemplos de uso da crase. Disponível em: <http://g1.globo.com/educacao/fotos/2012/03/vejafotos-com-exemplos-do-uso-da-crase.html\#F402412>. Acesso em: 19 mar. 2017.
} 
deste momento, será solicitado que os alunos tragam as reescritas de suas produções na próxima aula.

\subsection{Nono momento}

Objetivos: Exercitar o emprego da crase.

Neste momento, os alunos farão os seguintes exercícios:

1. Determine se a crase deve ser empregada nos exemplos abaixo. Em caso de dúvida, tente substituir a preposição por outra mais usada na fala; caso apareçam a preposição e o artigo, utilize a crase. Observe o exemplo:

- Pediram à senhorita. (Pediram para a senhorita)

a. A mãe agradava a filha.

b. Autorizo a senhora Beatriz a retirar os documentos.

c. Meu irmão gosta muito de ir a igreja.

d. Não vi aquilo.

e. Fui a Europa e voltei a noite.

f. O horário de fechamento será as 19 horas.

g. Proibido estacionar de segunda a sexta.

h. Agradeço a todos que me ajudaram.

i. A partir de hoje serei mais feliz.

2. Complete com à(s) ou a(s). Em caso de dúvida, troque a palavra feminina por uma palavra masculina; caso apareçam a preposição e o artigo, utilize a crase. Observe o exemplo:

- Pediram à senhorita. (Pediram ao senhor)

a. Enviarei esta proposta Vossa Excelência.

b. Estava disposto colaborar.

c. Meu dia dia é muito corrido.

d. A moradora distribuía alimentos pessoas carentes.

e. O moço deu informação errada. 
f. ___ direita fica a cozinha.

g. Flavio tem um carro álcool.

h. O motorista seguiu __ sinalização das ruas.

i. Não desejo __ ninguém uma carreira infeliz.

j. Escreveu um bilhete ___ lápis.

k. __ noite estava escura e os amigos foram praia ver a chegada dos pescadores que voltavam terra.

I. Estamos _ procura de alunos estudiosos.

\subsection{Décimo momento}

Objetivos: Dialogar sobre as dificuldades; publicar as produções, como forma de valorizar o trabalho do aluno; construir colaborativamente o conceito de crase.

Neste momento, será aberto um espaço para que os alunos possam falar sobre as suas principais dificuldades em escrever uma notícia e em assimilar o conteúdo crase, refletindo e socializando sobre o que acharam da temática e como se deu este processo de escrita.

Em seguida, os alunos serão guiados até o laboratório de informática para publicar suas produções em um grupo em uma rede social. Além disso, como atividade complementar, serão escolhidas as notícias mais criativas, para então se agendar e ir visitar alguns jornais locais, a fim de se verificar a possibilidade de efetuar uma publicação nestes jornais, conhecer um pouco dessa esfera e dialogar sobre este meio. Depois, os textos serão fixados no mural da escola.

Como um fechamento deste conteúdo, será proposta uma construção colaborativa do conceito de crase, com o diálogo sobre seu uso, não uso ou uso facultativo, a partir da pergunta: Em seu entendimento, o que é crase? Como saber se vai crase ou não? E para que ela serve?

Com estas atividades, que não se resumem a apresentar listas de regras, esperamos que seja possível construir saberes mais significativos. Como afirma Luft 
(2014, p. XII), “o que não adianta nada, mas nadinha de nada mesmo, são macetes, listas, decorebas. O atomismo didático pulveriza o saber, espalha confusão e insegurança".

\section{O fim da crise}

A simples memorização das regras gramaticais não é suficiente, no sentido de que não fará com que o aluno adquira domínio do conteúdo crase, principalmente porque as regras apresentam falhas na sua composição, dificultando assim a total compreensão. Além disso, a "decoreba" não relaciona este conteúdo a outros afins, abordando-os de forma compartimentalizada; isso dificulta não só a motivação para o aprendizado, mas também o desenvolvimento das habilidades de escrita e leitura, já que não incentiva a aplicação das regras em contextos legítimos de articulação da língua. Nesse sentido, é interessante trabalhar com as regras, mas interligadas à prática e ao uso, fazendo relações tanto cognitivas quanto conceituais.

É interessante construir dinâmicas, dar sentido aos conteúdos gramaticais, trabalhar com elementos culturais e fomentar questões acerca da realidade dos alunos, pois auxiliará o seu desenvolvimento intelectual e proporcionará um aprendizado, além da gramática para toda a vida. Pensando nisso, nossa tentativa foi de construir um ensino de crase sem crise: uma proposta na qual os saberes trazidos pelo aluno sobre este assunto são fundamentais.

Fundamentalmente, se objetivou trabalhar a clara relação entre crase e regência, partindo de uma única regra geral. O exemplo em discussão aqui é o ensino de crase, mas os passos traçados servem para qualquer conteúdo: conhecer os alunos, perceber suas dificuldades, diagnosticar seus principais problemas linguísticos, suscitar temáticas possíveis para serem abordadas, e posteriormente, construir uma proposta de ensino relacionado. Relacionar os conteúdos uns com os outros, e relacionar a gramática com o texto, é fundamental na construção de um saber de qualidade, pois as estruturas gramaticais da língua são interdependentes, e a gramática se realiza concretamente nos usos que fazemos da língua.

Acredita-se que esta pesquisa poderá auxiliar os professores de língua portuguesa a repensarem suas metodologias e fazerem da revisão um momento real de retomada, 
para que o conteúdo aprendido não fique solto. Será útil também para reflexões e aplicações práticas do conteúdo crase na vida escolar dos alunos, fazendo com que, através da proposta didática apresentada, sejam eles os centralizadores do saber - papel este, muitas vezes, atribuído ao professor.

Por fim, pode-se concluir que com professores mais dedicados, alunos mais participativos e documentos oficiais coerentes, podemos transformar as aulas de português em aulas dinâmicas, nas quais os conteúdos são interligados e os alunos interagem dialogicamente, promovendo reflexões, críticas e análises que irão favorecer a construção de cidadãos mais críticos e pensantes, que não apenas aceitam e decoram as regras, mas que contribuem para sua aplicação e utilização no meio em que vivem. Como afirma Luft (2014, p. 99): “não há nenhuma regra a decorar: basta o raciocínio”.

\section{Referências}

BAGNO, Marcos. Gramática pedagógica do português brasileiro. São Paulo: Parábola Editorial, 2012.

CEGALLA, Domingos Paschoal. Novíssima gramática da língua portuguesa. 48.ed. São Paulo: Companhia Editora Nacional, 2008.

DIONISIO, Angela Paiva; MACHADO, Anna Rachel; BEZERRA, Maria Auxiliadora. (Orgs.). Gêneros textuais e ensino. São Paulo: Parábola Editorial, 2010.

KLEIMAN, Angela; SEPULVEDA, Cida. Oficina de gramática. Campinas: Pontes, 2012.

LUFT, Celso Pedro. Decifrando a crase. 2.ed. São Paulo: Globo, 2014.

MOURA NEVES, Maria Helena de. Gramática na escola. 8.ed. São Paulo: Contexto, 2010. 
Recebido em: 02/05/2017 Aprovado em: 13/09/2017

Universidade do Estado de Santa Catarina - UDESC

Centro de Ciências Humanas e da Educação - FAED

Revista PerCursos

Volume 18 - Número 37 - Ano 2017 revistapercursos@gmail.com 